\title{
Crown pillar extraction with paste underhand stoping
}

\author{
A Shiels Glencore, Australia \\ D Sainsbury Geotechnica Pty Ltd, Australia
}

\begin{abstract}
Technical investigations were conducted for extraction of a high-grade crown pillar in the northern 3500 orebody (N3500) at Glencore's Mount Isa Mines using cemented paste backfill (CPB) underhand stoping. Several stopes have now been successfully extracted, achieving the planned recoveries with minimal dilution.

In addition to standard CPB lab testing, in situ testing was conducted in the area planned for underhand exposure. The objective was to determine the variance between actual and design CPB strengths, to ensure the strengths were suitable for the planned underhand exposure dimensions. The testing results indicated the majority of in situ CPB strengths were higher than the lab cured and design strengths, due to the arching of stresses within the fill mass and curing processes. The strength parameters obtained from the testwork were incorporated in numerical modelling assessments using FLAC3D. Model calibrations were conducted using historical vertical CPB exposures to ensure the adopted methodology and material parameters were suitable.

This paper discusses the methodology and results of the technical investigations, and how the data fed into analyses to assist with safe and efficient extraction of the crown pillar.
\end{abstract}

Keywords: crown pillar, paste underhand, stoping

\section{Introduction}

N3500 is a high-grade copper orebody situated in the northern part of the Enterprise Mine at Mount Isa Mines, located in northwest Queensland, Australia (Figure 1). Glencore's Mount Isa Mines has been in operation for almost 100 years. The current mining methods employed are sublevel open stoping with backfill and sublevel caving.

The N3500 orebody is the deepest orebody at Mount Isa Mines, with current mining at a depth of 1.4 to $2 \mathrm{~km}$ (Figure 2). The orebody is mined in several longitudinal panels, in a bottom up/centre-out retreat sequence, which has proven to be a successful practice to date. Stopes are filled with cemented paste backfill (CPB) then exposed vertically with the next stope in the sequence. In order to mine multiple panels at once, a crown pillar was left within the orebody from 28B to 29E sublevels, with dimensions of $100 \mathrm{~m}$ long (north-south), $40 \mathrm{~m}$ wide (east-west) and $60 \mathrm{~m}$ high.

To optimise extraction of the N3500 orebody, undercutting of the CPB was considered. The 29A block was identified for underhand exposure, situated in a crown pillar, underneath the $28 \mathrm{~B}$ and adjacent $30 \mathrm{~A}$ previously mined and filled stopes. The extraction sequence requires both vertical and underhand exposure of the paste filled stopes. Standard CPB design strengths in the area are 600 to $800 \mathrm{kPa}$ from the base to 25 to $50 \mathrm{~m}$, with 400 to $500 \mathrm{kPa}$ for the remainder. The underhand exposures must be strong enough to prevent failure of the entire fill mass and major sloughing of the vertical and underhand exposure faces.

The planned 29A stoping block consists of seven stopes with dimensions of 20 to $30 \mathrm{~m}$ (L), $25 \mathrm{~m}(\mathrm{~W})$ and $60 \mathrm{~m} \mathrm{(H)}$ and sizes of 60,000 to 90,000 tonnes (Figure 3). 


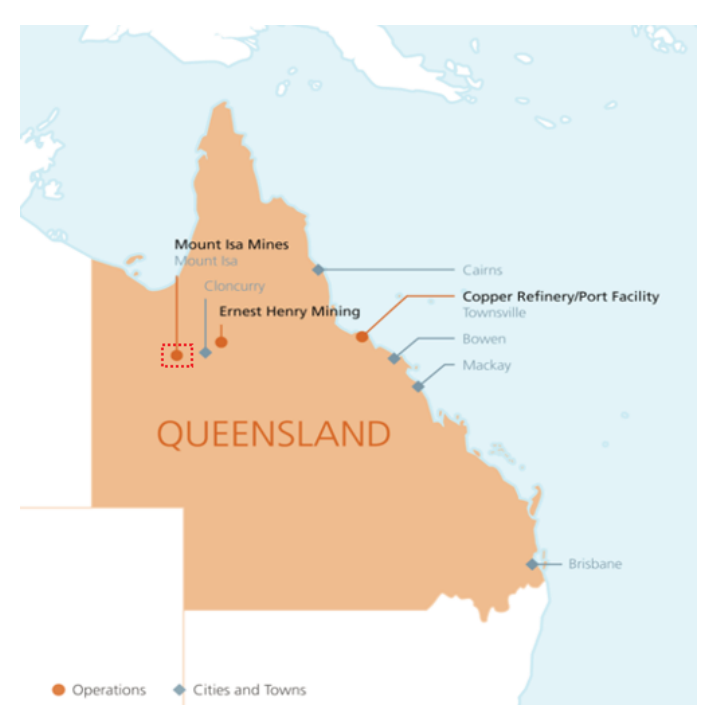

Figure 1 Mount Isa Mines is located in northwest Queensland, Australia

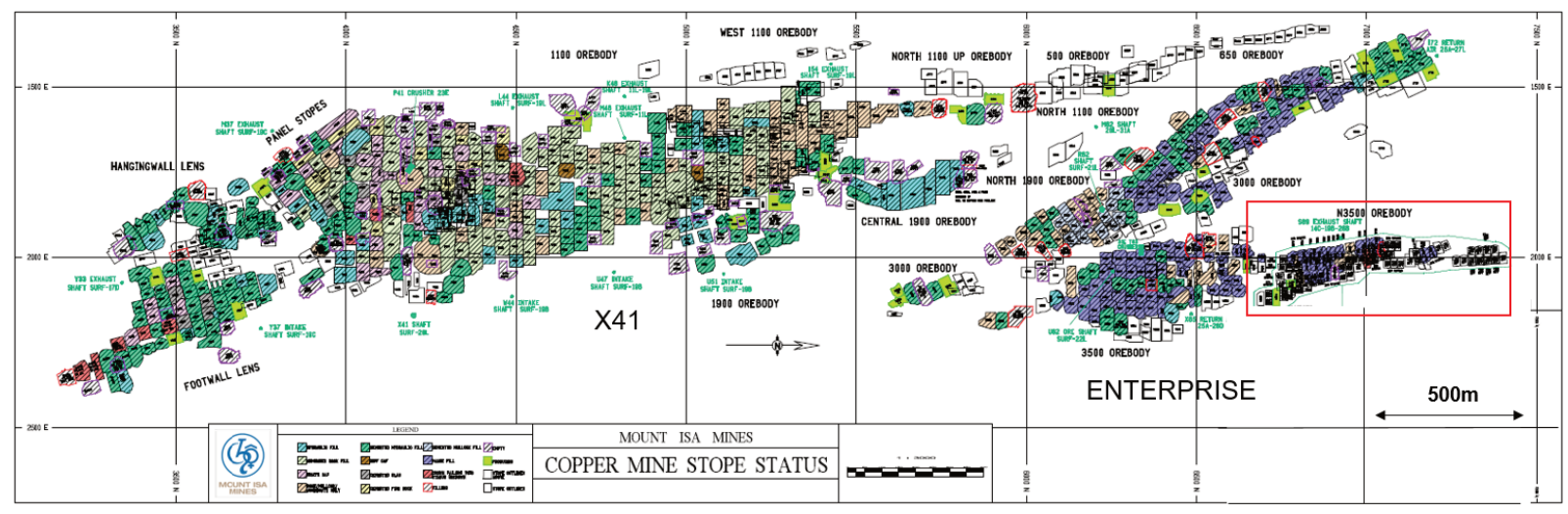

Figure 2 Plan view of Mount Isa Mines stope mine status with the N3500 orebody

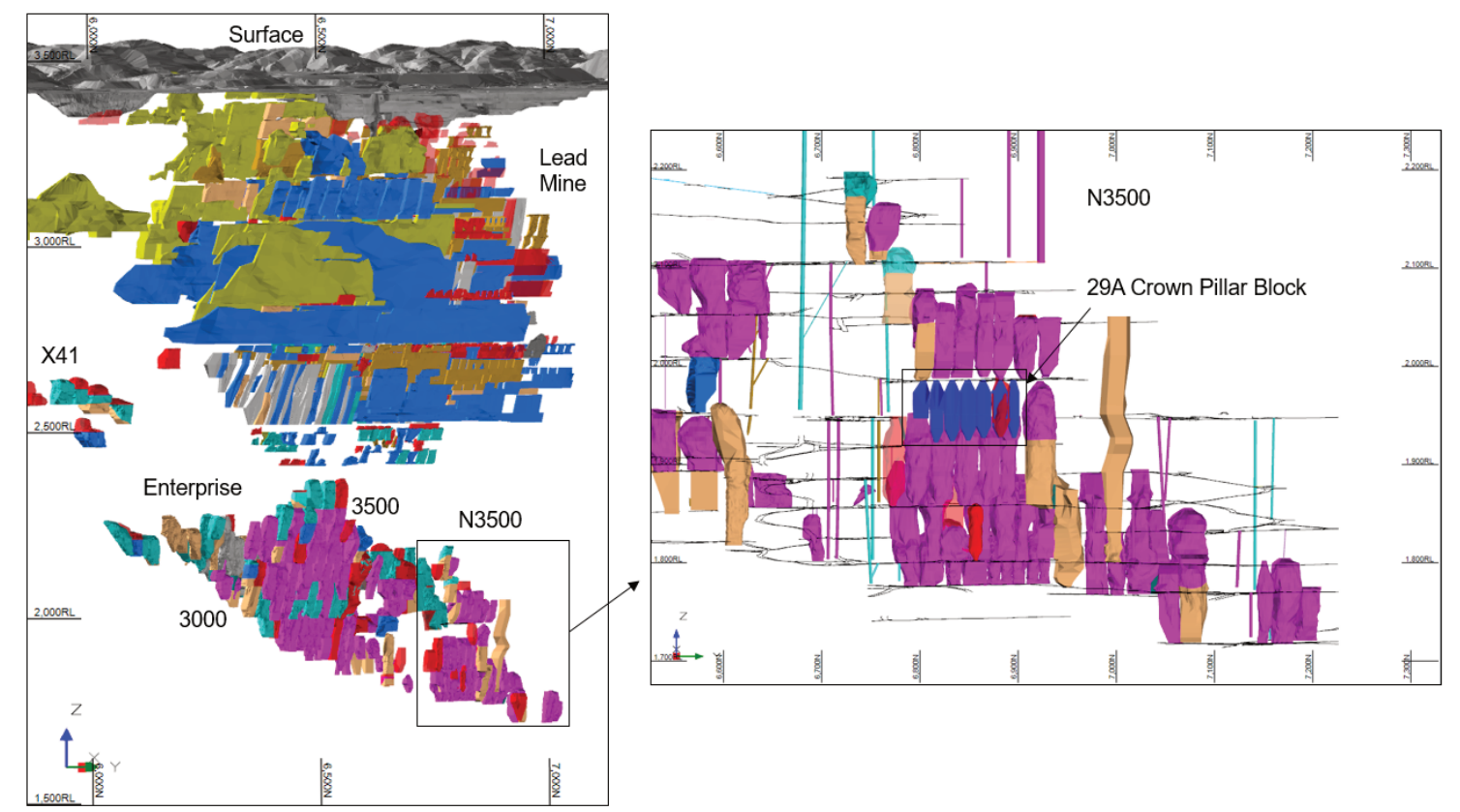

(a)

(b)

Figure 3 Location of the N3500 orebody and 29A stoping block with adjacent orebodies at Mount Isa Mines, looking (a) Northwest and (b) West 


\section{$2 \quad$ N3500 orebody}

\subsection{Geological setting}

The N3500 orebody strikes north-south, dipping at 60 to 70 degrees to the west. It has two bounding structures which define the orebody; the basement contact zone (BCZ) which forms the lower boundary, and the footwall fault zone which forms the eastern boundary. The BCZ dips at 35 to 45 degrees to the northeast consisting of highly sheared and faulted carbonaceous mylonite of up $25 \mathrm{~m}$ thickness. The footwall fault steeply dips to the west exhibiting high talc concentrations and minor graphite, and moderate to strong shearing with an average thickness of $7 \mathrm{~m}$.

The orebody is hosted within Urquhart shales, with rock types consisting of predominantly fractured siliceous shale with lesser irregularly brecciated shales. Rock types in the hanging wall consist of recrystallised shale and dolomitic shales. Rock types in the footwall consists of dolomitic shales, pyritic shales and slaty shales.

Several significant fault zones are also present which offset the orebody (Figure 4). The faults can be divided into two sets; the north-south (NS) west dipping faults and the north-northwest (NNW) near vertical dipping faults, exhibiting strong graphitic shearing and talcose alteration.

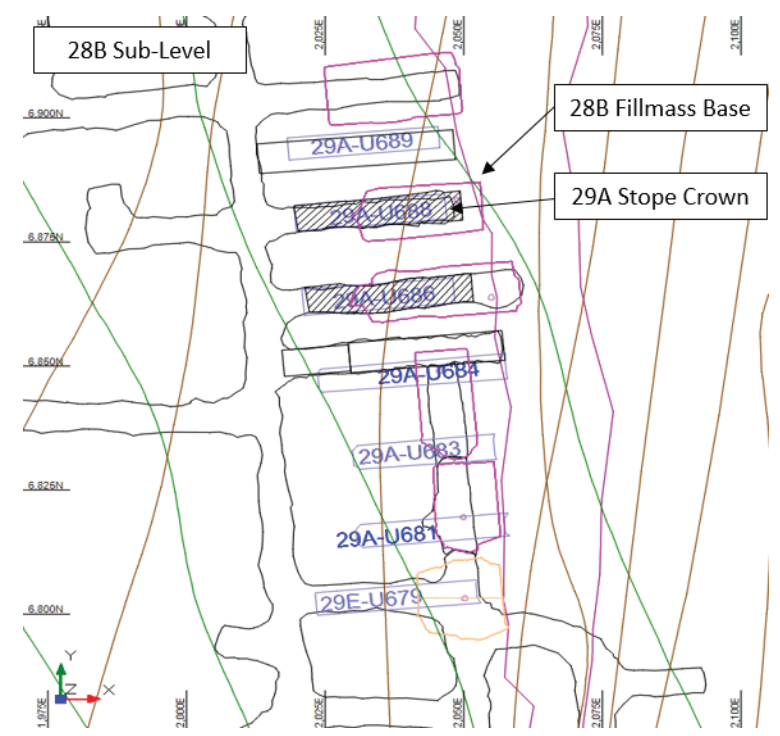

Figure 4 Plan view with 28B development, major structures, planned 29A stope crowns (blue), 28B fill mass bases (pink), north-northwest faults (green), north-south faults (brown) and footwall fault (pink)

\subsection{Geotechnical setting}

Rock mass conditions in the N3500 orebody are highly variable, with very poor zones of talc-altered shale, fissile graphitic shale, numerous faults and moderate in situ stress conditions, resulting in an extremely deformable rock mass. The breccia orebody outside of fault zones is extremely competent and generally massive, defined by the $>2.0 \%$ copper shell.

Three main geotechnical domains have been established based on fracture frequency per metre $(\mathrm{FF} / \mathrm{m})$, talc alteration and copper mineralisation (Sainsbury \& Grubb 2010) (Table 1).

Table 1 Geotechnical domains with properties

\begin{tabular}{llll}
\hline Geotechnical domain & FF/m & Talc content (\%) & Rock mass rating \\
\hline Hanging wall & $5-10$ & $<10.0$ & Fair \\
Orebody & $0-5$ & 0.0 & Good \\
Footwall & $>10$ & $>15.0$ & Poor \\
\hline
\end{tabular}




\subsection{Stress regime}

Since the late 1960s, significant rock stress measurements have been completed at Mount Isa Mines, including in excess of 30 virgin (pre-mining) and 70 mining-induced measurements. Significant damage mapping has also been conducted in the N3500 orebody, with ample evidence of high stress spalling in the backs of the east-west crosscuts to support a north-south oriented major principle stress.

The stress magnitudes and orientations for the N3500 orebody are presented in Table 2. The 29A block is located approximately $1.7 \mathrm{~km}$ below surface resulting in a major and minor principle stress of approximately 64 and 44 MPa respectively.

Table 2 Pre-mining stress fields used for numerical modelling in the N3500 orebody

\begin{tabular}{llll}
\hline & Magnitude (MPa/m) & Dip (degrees) & Dip direction (degrees) \\
\hline$\sigma_{1}$ & 0.037 & 5 & 176 \\
$\sigma_{2}$ & 0.026 & 71 & 281 \\
$\sigma_{3}$ & 0.024 & 18 & 85 \\
\hline
\end{tabular}

\subsection{Previous mining performance}

Extraction of stopes in N3500 has generally been successful to date. Minor overbreak generally occurs along the west hanging wall and east walls, which is structurally controlled by the bedding planes and major structures with graphitic shearing and talc. On rare occasions, large failures from the eastern walls have occurred associated with a strong presence of talc content, which can exceed over $30 \%$ of the rock mass. The talc significantly reduces the rock mass strength and joint conditions. The north and south walls encounter little overbreak as these are oriented perpendicular to structures. The stope design methodology is to keep the walls within the high-grade orebody breccia and better ground conditions. The vertical CPB exposures can be up to $120 \mathrm{~m}$ high and remain stable with only minor fill dilution. This is due to:

- Adequate curing of the fill mass prior to exposure (28 days for stope firings).

- Effective blasting practices.

- A minimum 2 to $3 \mathrm{~m}$ skin pillar is left when blasting adjacent to the fill mass.

- Where practical, holes are drilled parallel to the fill mass rather than toeing into the fill mass.

- Boundary rings are charged with low density Sanfold explosives (a Dyno Nobel product).

- Limited cold jointing; following the capping run, CPB is continuously run for stopes in the area.

- Arching of stresses within the fill mass and curing processes increasing the in situ strength.

\section{$3 \quad$ Mine design}

The 29A block consists of seven stopes with dimensions of 20 to $30 \mathrm{~m}(\mathrm{~L})$ by $25 \mathrm{~m}(\mathrm{~W})$ by $60 \mathrm{~m}(\mathrm{H})$ and sizes of approximately 60,000 to 90,000 tonnes. The stope crowns are situated on 28B with single drawpoints on 29A. Access is gained to the top of the stope by development fill mining through the base of the previously extracted, filled and cured stope on 28B. Upholes are drilled from 29A with all downholes drilled from a single drive on $28 \mathrm{~B}$. A retreat sequence from north to south was adopted to assist with management of stress during the extraction of the crown pillar. Each stope is filled with CPB following completion, then vertically exposed with the next stope in the sequence.

The stopes are fired as a vertical retreat, with a single $1.1 \mathrm{~m}$ diameter raisebore extending the full height of the stope. The firing sequence includes a trough undercut from the drawpoint level followed by several downhole firings (Figure 5). The final firing is approximately $20 \mathrm{~m}$ below the $28 \mathrm{~B}$ level. 
29A-U688 was the first stope in the block to be extracted. It is positioned directly below the 28B-U688 stope, with a design $\mathrm{CPB}$ strength of $800 \mathrm{kPa}$ (the in situ strength was found to be $1,360 \mathrm{kPa}$ ). The dimensions of 28B-U688 are $20 \mathrm{~m} \mathrm{(L),} 40 \mathrm{~m}(\mathrm{~W})$ and $90 \mathrm{~m}(\mathrm{H})$. To the west of the stope lies the 30A-U687 filled stope, which makes up a portion of the west footwall of 29A-U688.

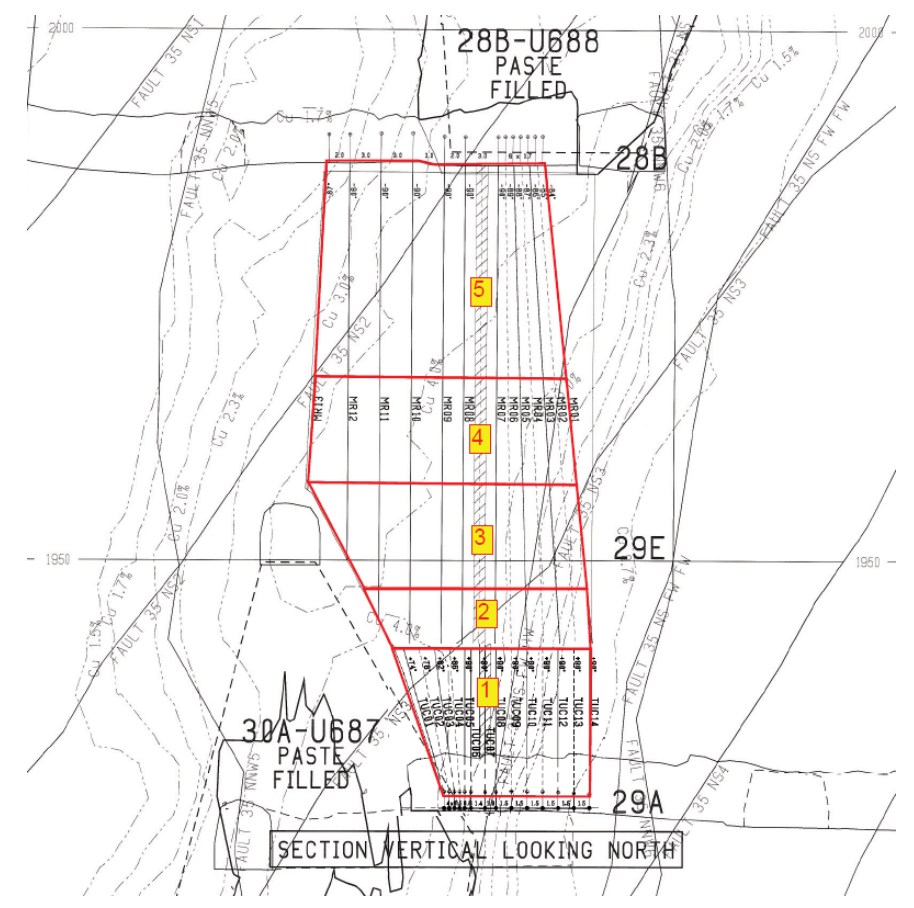

Figure 5 Cross-section looking north with the 29A-U688 stope and firing sequence

\section{$4 \quad$ Technical investigations}

\subsection{Cemented paste backfill background}

The CPB is sourced from the paste fill plant which is fed from tailings from two concentrators (copper and zinc streams). Metallurgical slags are frequently processed through the copper stream. The complexity of paste production is largely driven by the range of supply and process variations that can affect one aspect of fill quality, namely the particle size distribution (PSD). The PSD affects the rheology and strength performance of the CPB. Despite the PSD variations, these still remain within the required sizing criteria for the CPB (AMC Consultants 2012).

A second key quality parameter is that of fill slurry density. This is significantly variable relating to the successful delivery underground by gravity pipeline and due to the resulting backfill strength for a particular binder content and curing time (AMC Consultants 2012).

\subsection{In situ sampling program}

Bulk samples were extracted from inside the filled stope during development fill mining. The samples were taken to the site core shed for preparation and testing.

A total of 16 in situ CPB locations were sampled and tested during 2017 and 2018 from within the orebody. Inspection of each development fill face was conducted with a photo log taken to ascertain if any cold jointing or excessive layering was present. None was identified during inspections.

An example of a bulk CPB sample taken during development fill mining is illustrated in Figure 6 . 


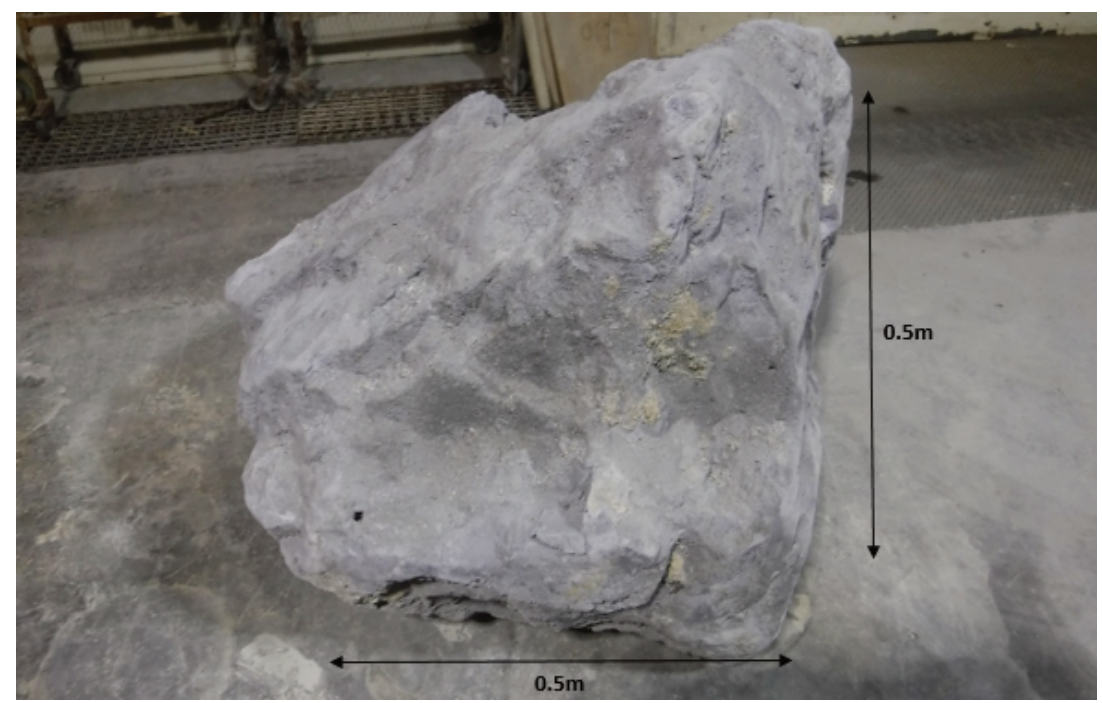

Figure 6 Bulk cemented paste backfill sample taken during development fill mining

\subsection{Lab testing}

The bulk samples were cored without water into cylinders of $50 \mathrm{~mm}$ diameter and $100 \mathrm{~mm}$ length in preparation for unconfined compressive strength (UCS) and multi-stage triaxial testing. Sampling numbers varied between locations due to availability of adequate bulk samples.

Examples of prepared samples ready for testing are illustrated in Figure 7.

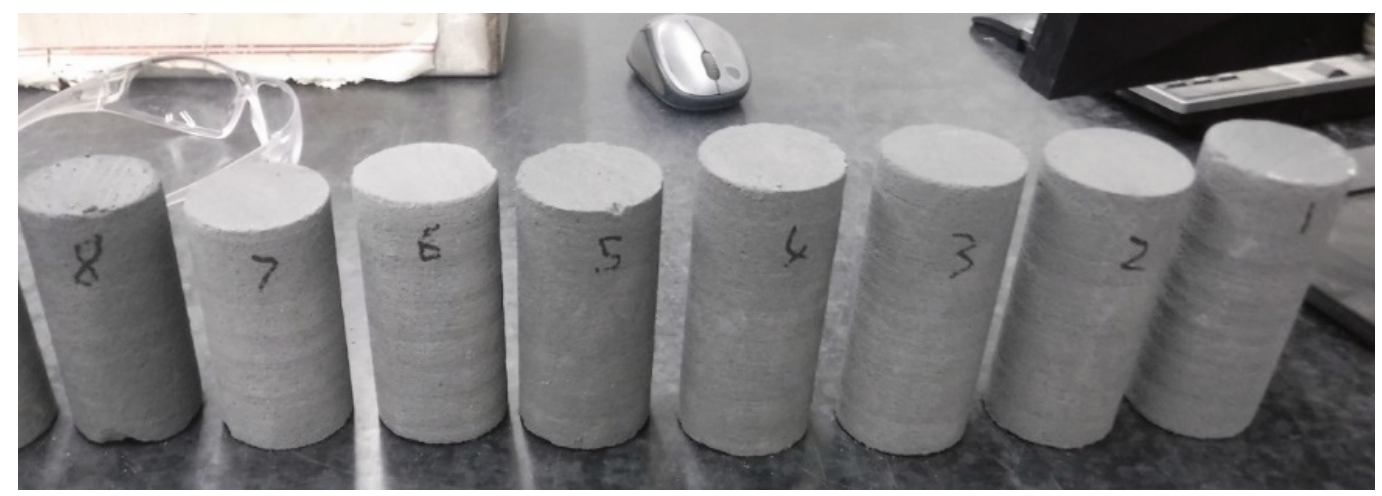

(a)

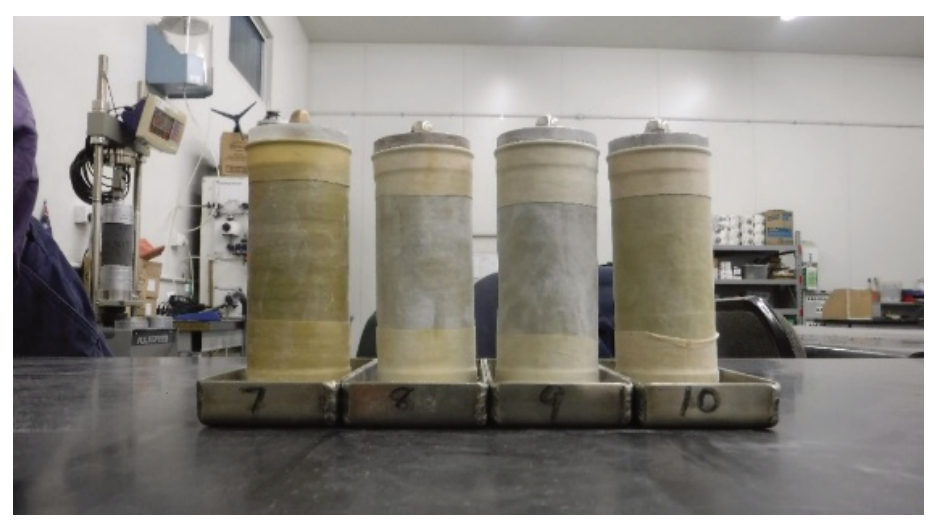

(b)

Figure 7 In situ cemented paste backfill samples ready for (a) Unconfined compressive strength; and (b) Triaxial testing 


\subsection{Results}

The UCS test results are presented in Table 3 and Figure 8. The design CPB strength at each extracted in situ sample location and lab CPB strength (cured in the surface lab) are also included for comparison.

The results show the in situ CPB strengths were mostly higher than both the lab cured and design strength. This can be attributed to:

- Arching of stresses within the fill mass.

- Large size and height of the stopes.

- Curing processes increasing the in situ strength, including;

○ Fast rate of filling.

- Long travel times increasing mixing and de-hydrating.

$\circ$ High in situ temperatures.

Several results show significant increases in strength between the design and in situ CPB, thought to be due to the addition of lead slag in the CPB mix design and location of the in situ sample that was sourced from the base of the stope where the vertical stresses and arching would be the most influential.

The high strength in situ results observed could also be a function of the bulk sampling. The larger bulk samples could be higher in strength, which may result in sampling bias. In situ drilling was not conducted during the investigations; this may have led to more representative results.

Table 3 Unconfined compressive strength (UCS) results from the in situ and lab CPB testing with design UCS (standard deviation in parenthesis)

\begin{tabular}{|c|c|c|c|c|c|c|c|c|}
\hline $\begin{array}{l}\text { Sample } \\
\#\end{array}$ & $\begin{array}{l}\text { Sample ID } \\
\text { (location) }\end{array}$ & $\begin{array}{l}\text { Design } \\
\text { (UCS) } \\
(\mathrm{kPa})\end{array}$ & $\begin{array}{l}\text { In situ UCS } \\
(\mathrm{kPa})\end{array}$ & $\begin{array}{l}\text { \# in situ } \\
\text { tests }\end{array}$ & $\begin{array}{l}\text { In situ cure } \\
\text { time (days) }\end{array}$ & $\begin{array}{l}\text { Lab UCS } \\
(\mathrm{kPa})\end{array}$ & $\begin{array}{l}\text { \# lab } \\
\text { tests }\end{array}$ & $\begin{array}{l}\text { Lab cure } \\
\text { time } \\
\text { (days) }\end{array}$ \\
\hline 1 & 32D-U679 (31A) & 400 & $424(128)$ & 24 & $>56$ & $460(170)$ & 2 & $>28$ \\
\hline 2 & 32D-T681 (32D) & 600 & $633(131)$ & 26 & $>56$ & & & $>28$ \\
\hline 3 & $30 A-U 687(29 A)$ & 500 & $324(26)$ & 2 & 14 & 310 & 1 & $>28$ \\
\hline 4 & 28B-U682 (28B) & 600 & $1,380(226)$ & 9 & $>56$ & 670 & 1 & $>28$ \\
\hline 5 & 28B-U682 (27A) & 300 & 277 & 1 & $>56$ & & & $>28$ \\
\hline 6 & 28B-U686 (28B) & 700 & $1,030(175)$ & 25 & $>56$ & 590 & 1 & $>28$ \\
\hline 7 & $30 A-U 685(29 A)$ & 600 & $926(47)$ & 3 & 28 & $540(50)$ & 5 & $>28$ \\
\hline 8 & $30 A-U 687$ (30A) & 700 & $1,139(531)$ & 7 & $>56$ & $598(113)$ & 5 & $>28$ \\
\hline 9 & $30 A-U 689(30 A)$ & 600 & $1,122(581)$ & 2 & $>56$ & 1,180 & 1 & $>28$ \\
\hline 10 & 33D-T719 (33D) & 600 & $698(223)$ & 20 & 30 & $310(60)$ & 2 & $>28$ \\
\hline 11 & 33D-T719 (32D) & 400 & $159(70)$ & 3 & 20 & $265(40)$ & 6 & $>28$ \\
\hline 12 & 30A-T663 (30E) & 300 & $1,131(351)$ & 6 & $>56$ & $350(33)$ & 1 & $>28$ \\
\hline 13 & 31A-T701 (30A) & 500 & 2,667 (249) & 3 & 31 & $1,270(150)$ & 2 & $>28$ \\
\hline 14 & 31A-T701 (31A) & 800 & $973(148)$ & 7 & 31 & $630(30)$ & 10 & $>28$ \\
\hline 15 & 30A-U683 (29E) & 400 & $1,053(100)$ & 2 & $>56$ & $560(90)$ & 1 & $>28$ \\
\hline 16 & 28B-U688 (28B) & 800 & $1,360(300)$ & 4 & $>56$ & $600(100)$ & 6 & $>28$ \\
\hline
\end{tabular}




\section{In situ, lab and design strengths (>28 days curing)}

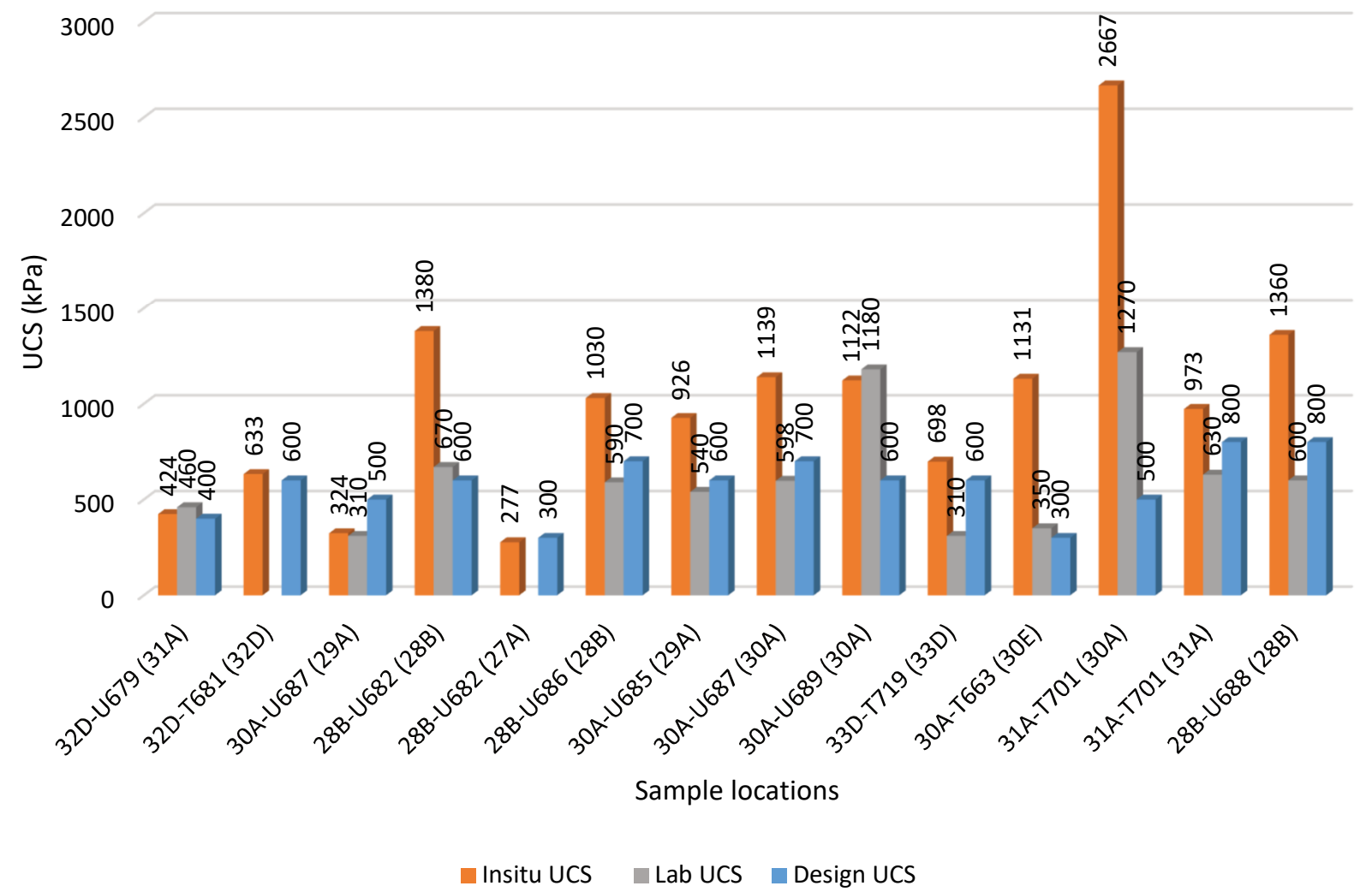

Figure 8 In situ, lab and design strengths from unconfined compressive strength testing (greater than 28 days curing)

Triaxial test results for the in situ CPB samples are presented in Table 4. The average friction angle was approximately 30 degrees, which is consistent with Brummer et al.'s (2003) hypothesis that a friction angle of 30 degrees is typical of most CPB materials. The cohesion was found to increase as a function of the UCS.

Table 4 In situ shear strength results from triaxial testing (standard deviation in parenthesis)

\begin{tabular}{lllllll}
\hline Sample \# & $\begin{array}{l}\text { Sample ID } \\
\text { (location) }\end{array}$ & $\begin{array}{l}\text { In situ UCS } \\
(\mathbf{k P a})\end{array}$ & $\begin{array}{l}\text { \# in situ } \\
\text { tests }\end{array}$ & $\begin{array}{l}\text { Cohesion } \\
(\mathbf{k P a})\end{array}$ & $\begin{array}{l}\text { Friction } \\
\text { angle ( }\end{array}$ & $\begin{array}{l}\text { Cure time } \\
(\text { days })\end{array}$ \\
\hline 10 & 33D-T719 (33D) & $698(223)$ & 5 & 300 & 35.0 & 30 \\
12 & $30 \mathrm{~A}-\mathrm{T663}(30 \mathrm{E})$ & $1,131(351)$ & 4 & 400 & 25.4 & $>56$ \\
13 & $31 \mathrm{~A}-\mathrm{T701}(30 \mathrm{~A})$ & $2,667(249)$ & 2 & 475 & 29.9 & 31 \\
14 & $31 \mathrm{~A}-\mathrm{T701}(31 \mathrm{~A})$ & $973(148)$ & 2 & 400 & 31.0 & 31 \\
16 & 28B-U688 (28B) & $1,360(300)$ & 6 & 250 & 32.0 & $>56$ \\
\hline
\end{tabular}

UCS data as a function of varying binder percent (general purpose coarse cement - GPC) and curing time was also investigated (Figure 9). The relationship between curing time and UCS was used to simulate the strength gain of the CPB. The numerical analyses assumed each stope was filled in $5 \mathrm{~m}$ high increments. The adopted strength gain relations are consistent with published early-age testing on CPB (Veenstra 2013). 


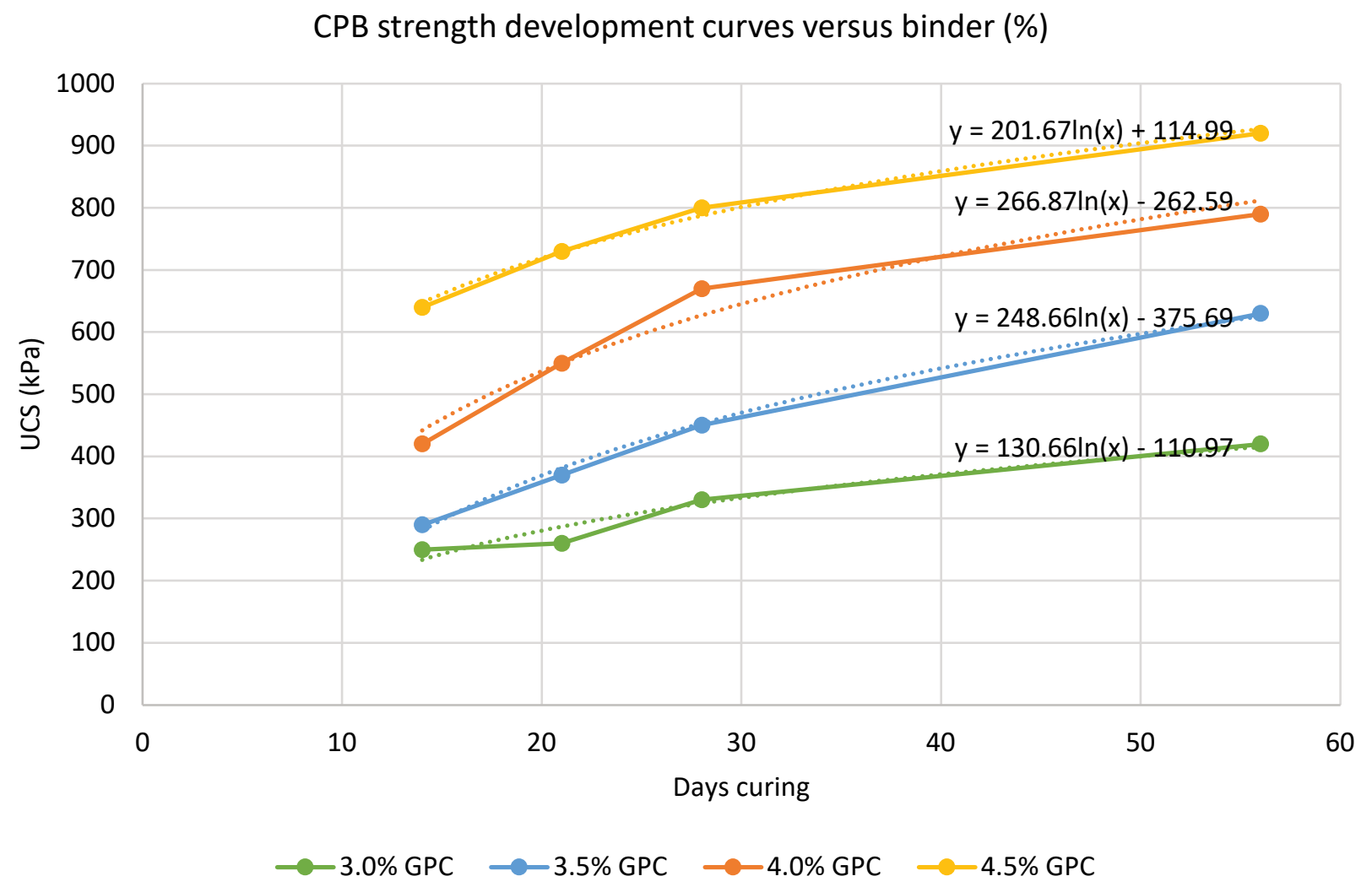

Figure 9 Lab cured strength development curves as a function of binder percent

\section{$5 \quad$ Numerical modelling}

\subsection{Modelling approach}

The underhand exposures must be strong enough to prevent failure of the entire fill mass and major sloughing of the vertical and underhand exposure faces. Paste fill exposure stability is a function of the following:

- Exposure geometry.

- Stope extraction and filling sequence.

- Hanging wall-footwall closure.

- Surrounding rock mass failure.

- Initial stresses within the fill mass.

- Internal cold joints or segregation within the fill mass.

- Dimensions of the fill mass.

- Shear strength of the fill.

The modelling approach adopted to investigate stability of the paste fill exposures included the following:

- Construction of a series of numerical models with the three-dimensional finite difference program FLAC3D. The model was constructed to simulate the historical extraction and filling sequence within the $\mathrm{N} 3500$ orebody. It is important to accurately simulate the filling and hydration sequence of each stope to provide a rigorous assessment of the internal stress distribution (arching) within each fill mass. 
- The model was also constructed to simulate yielding and deformation within the rock mass surrounding each stope as potential fill failure mechanisms may involve failure of the yielded rock at the stope abutments.

- Calibration of previous vertical paste fill exposure performance was conducted using historic data. The calibration is critical to ensure the adopted modelling methodology and material properties that were used have a high level of confidence in predicting future underhand exposure performance.

- A series of predictive analysis was conducted to assess the performance of the underhand exposures that would be created by extraction of the planned 29A stoping block.

\subsection{Model parameters}

The rock mass surrounding the N3500 stopes has been simulated with a bi-linear, Mohr-Coulomb, strain softening constitutive model. The Mohr-Coulomb criterion has been used to define the peak strength of the rock mass (cohesion and friction) through a least-squares fit to the Hoek-Brown envelope developed from estimates of the Geological Strength Index (GSI), UCS $\left(\sigma_{\mathrm{ci}}\right)$ and $m_{\mathrm{i}}$ for the hanging wall, orebody and footwall domains. The Hoek-Brown parameters estimated for each domain are presented in Table 5.

Table 5 Hoek-Brown parameters for each domain

\begin{tabular}{llll}
\hline Domain & $\mathbf{G S I}$ & $\boldsymbol{\sigma}_{\mathrm{ci}}$ & $\mathbf{m}_{\mathbf{i}}$ \\
\hline Hanging wall & 55 & 110 & 10 \\
Orebody & 67 & 160 & 8 \\
Footwall & 50 & 95 & 10 \\
\hline
\end{tabular}

The CPB properties adopted for the analyses are presented in Table 6. The adopted Poisson's ratio ( $v$ ) and friction angle $(\Phi)$ values were assumed to be constant regardless of fill strength. Based on the site laboratory testing conducted for the $\mathrm{CPB}$, the remaining strength values were increased relative to the UCS. 600 and $400 \mathrm{kPa}$ UCS values were adopted as a conservative measure until the method of extraction was proven.

Table 6 Cemented paste backfill properties adopted for the exposure stability analyses

\begin{tabular}{llll}
\hline $\begin{array}{l}\text { Unconfined compressive } \\
\text { strength (kPa) }\end{array}$ & $\mathbf{2 0 0}$ & $\mathbf{4 0 0}$ & $\mathbf{6 0 0}$ \\
\hline Friction angle (degrees) & 30 & 30 & 30 \\
Cohesion (kPa) & 100 & 160 & 250 \\
Young's modulus (MPa) & 14 & 26 & 41 \\
Tensile strength (kPa) & 40 & 80 & 120 \\
Density $\left(\mathrm{kg} / \mathrm{m}^{3}\right)$ & 2,100 & 2,100 & 2,100 \\
\hline
\end{tabular}

\subsection{Model geometry}

A panel scale FLAC3D model was developed to represent the typical stope geometries and sequence planned in the 28B and 29A blocks (Figure 10). The surrounding rock mass has been included in the model to simulate damage and subsequent hanging wall-footwall closure during the extraction sequence.

The stopes surrounding the $28 \mathrm{~B}$ and $29 \mathrm{~A}$ blocks were simulated in the model as a single mining step, while each individual stope within $28 \mathrm{~B}$ and $29 \mathrm{~A}$ was excavated in sequence and filled with $5 \mathrm{~m}$ lifts to ensure an accurate representation of the stress path with the rock mass and each fill mass. 


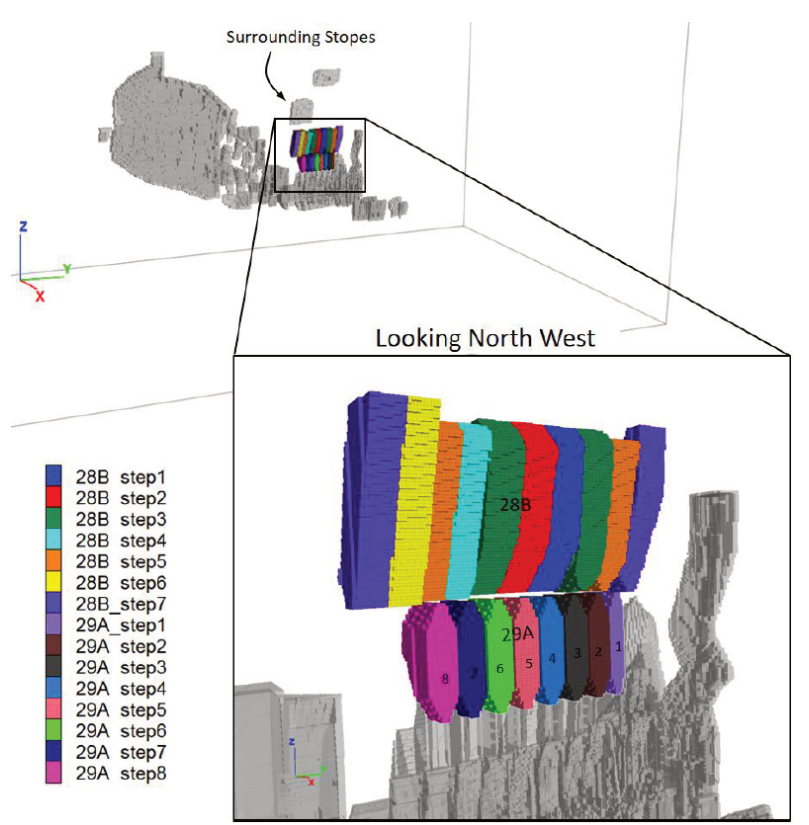

Figure 10 Regional model extents (top) and simulated stope sequence (bottom), looking northwest

\subsection{Analysis of vertical exposure performance}

All vertical fill mass exposures created with the extraction sequence were predicted to remain stable, with only minor damage (softening) at the perimeter of the fill masses. Figure 11a illustrates the predicted cohesion degradation (softening) and displacement after vertical exposure of a typical 28B stope (Figure 11b) and internal stresses. Although the fill mass remains stable, minor damage of the CPB can be observed.

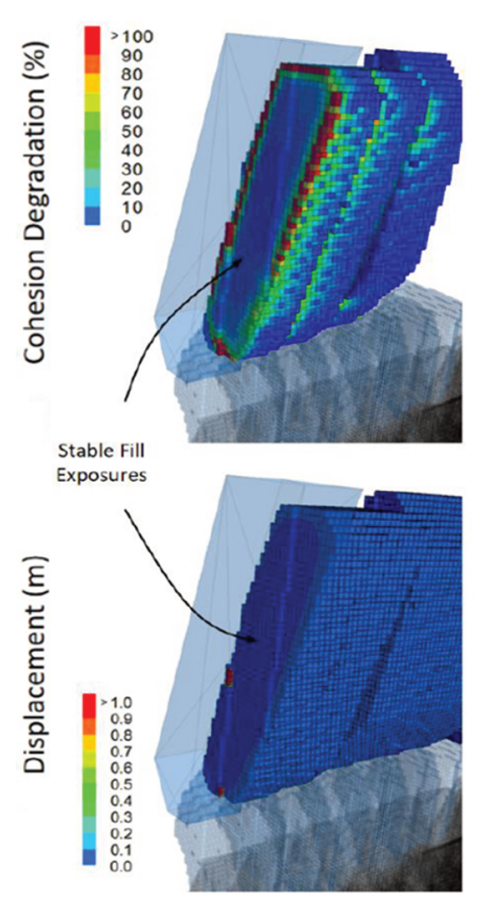

(a)

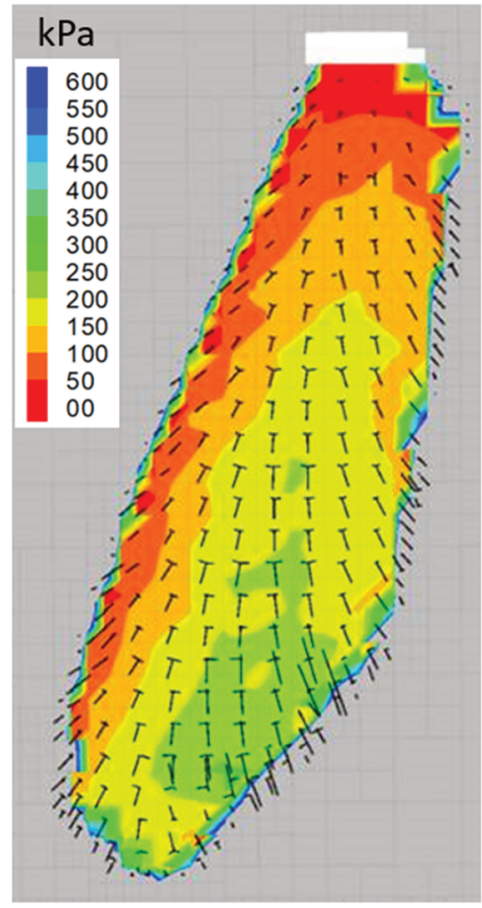

(b)

Figure 11 (a) Failure condition of the vertical exposure of a 28B stope above the future 29A block; (b) Internal stresses simulated within a 28B stope 


\subsection{Analysis of 29A block underhand exposure stability}

Multiple analyses were conducted to determine the performance of the underhand CPB exposures created during extraction of the 29A stopes. In this case, the strength (UCS) of all CPB was $600 \mathrm{kPa}$. The CPB was assumed to be homogenous, unsaturated and with no cold joints.

Failure is defined as collapse of the adjacent vertical or horizontal CPB exposure. In the models, this is indicated by the formation of an active failure surface and continuous displacement $(>1 \mathrm{~m})$ of portions of the fill mass.

Figure 12 illustrates the predicted cohesion degradation (softening) and displacement of exposures created at steps 2, 6 and 8. The underhand exposures created at steps 2, 6 and 8 are predicted to remain stable. Minor, localised dilution can be expected, as illustrated in step 8.

Significant rock mass yielding was predicted within the small pillars at the base of the $28 \mathrm{~B}$ level stopes.

Step 2

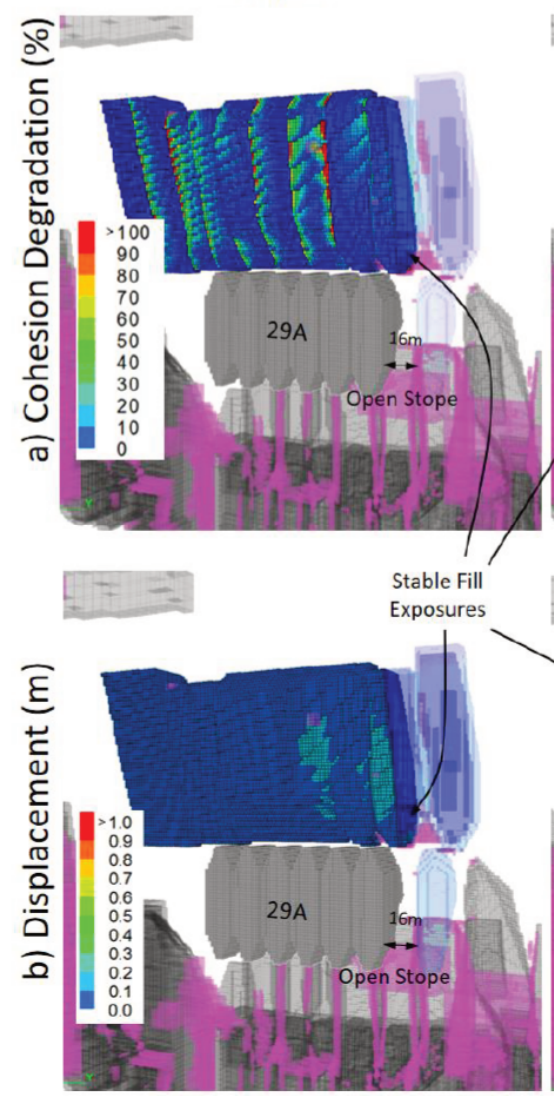

Step 6
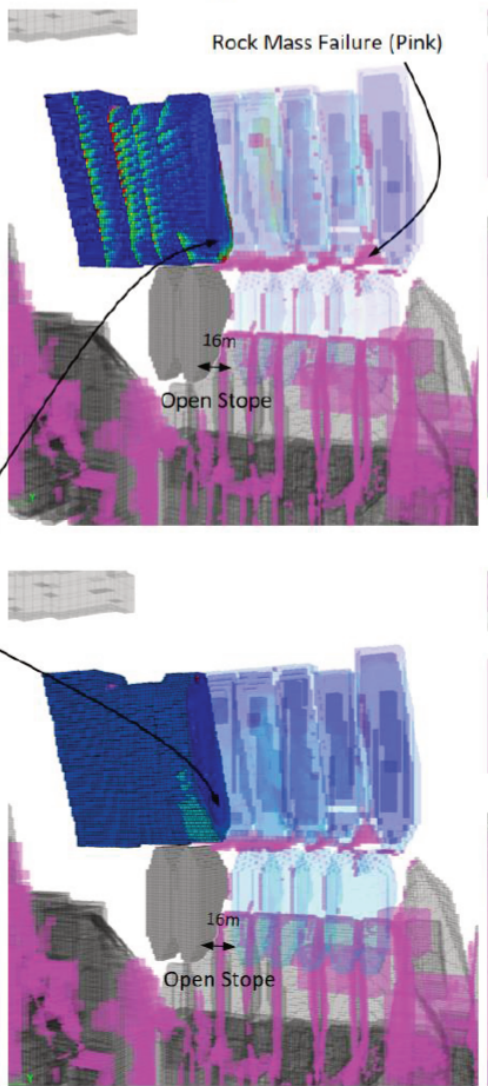

Step 8

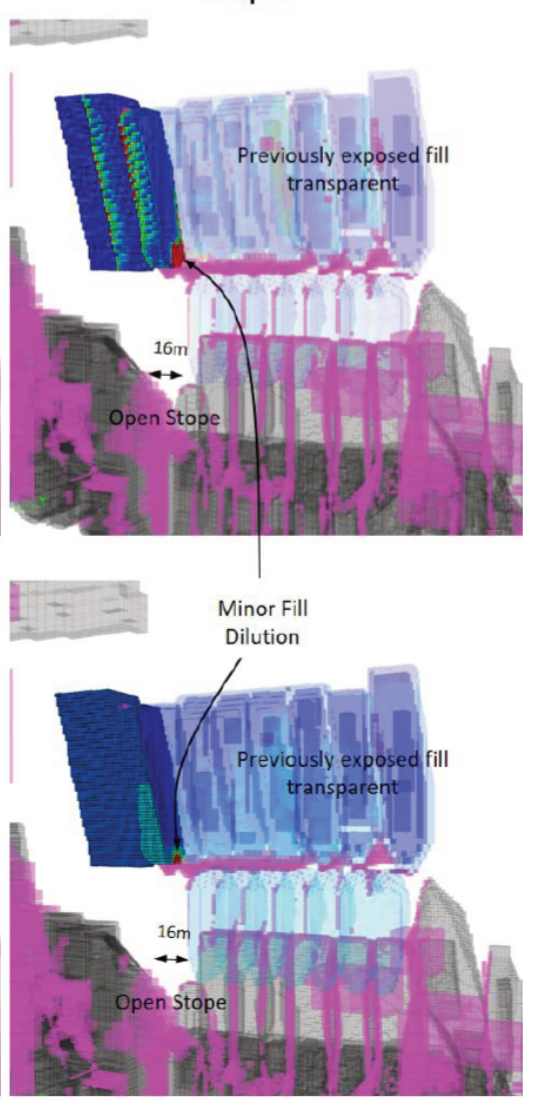

Figure 12 Failure condition predicted throughout the 29A extraction sequence. $600 \mathrm{kPa}$ fill mass

An additional analysis was conducted to investigate the performance of the underhand CPB exposures of $400 \mathrm{kPa}$ strength. Only a minor increase in deformation and cohesion degradation of the exposed CPB was predicted, indicating the in situ $(600 \mathrm{kPa}) 28 \mathrm{~B}$ fill mass has a Factor of Safety of at least 1.5 to maintain stability during underhand exposure from the 29A stopes.

\section{$6 \quad 29 A$ mining performance}

Two stopes have been successfully extracted from the 29A stoping block with mining of the third stope in progress (Figures 13 and 14). The underhand exposures were both stable and achieved the planned recoveries with minimal dilution. 
No additional ground support was installed in the stope crown on 28B. Difficulties were encountered during production drilling from the single downhole drill drive on $28 \mathrm{~B}$ due to poor and damaged rock mass. The single drill drive also meant drill holes required toeing into the north and south walls. Traditional practice involves a low density boundary ring parallel to these walls which results in better recovery and less damage. A good result was still achieved, with some minor underbreak occurring on the north and south walls.

The remaining stopes in the sequence are being optimised to increase the planned underhand exposure dimensions and overall efficiency of the block extraction with a risk-based approach.

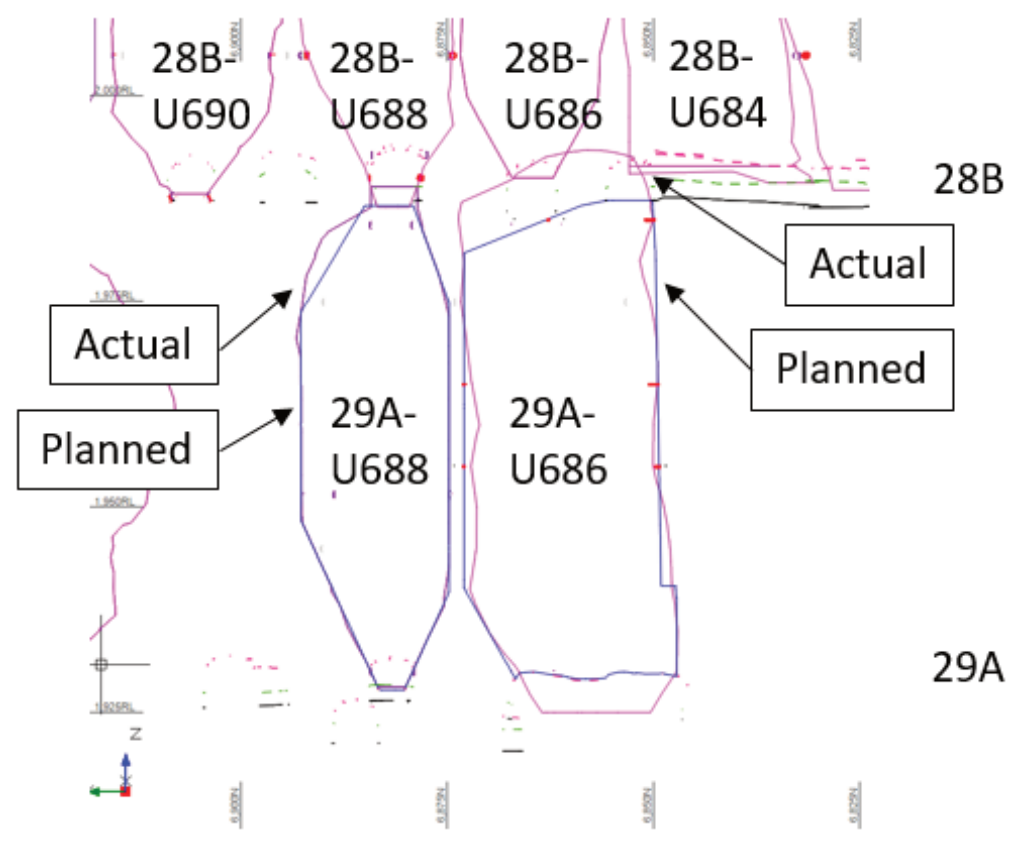

Figure 13 Long section east with planned (blue) and actual (pink) 29A-U688 and 29A-U686 extracted stopes

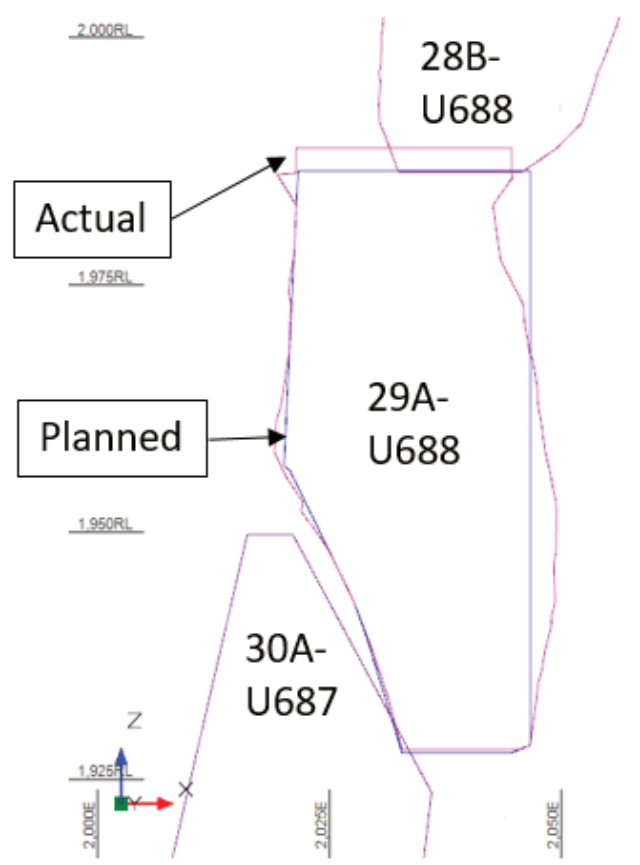

(a)

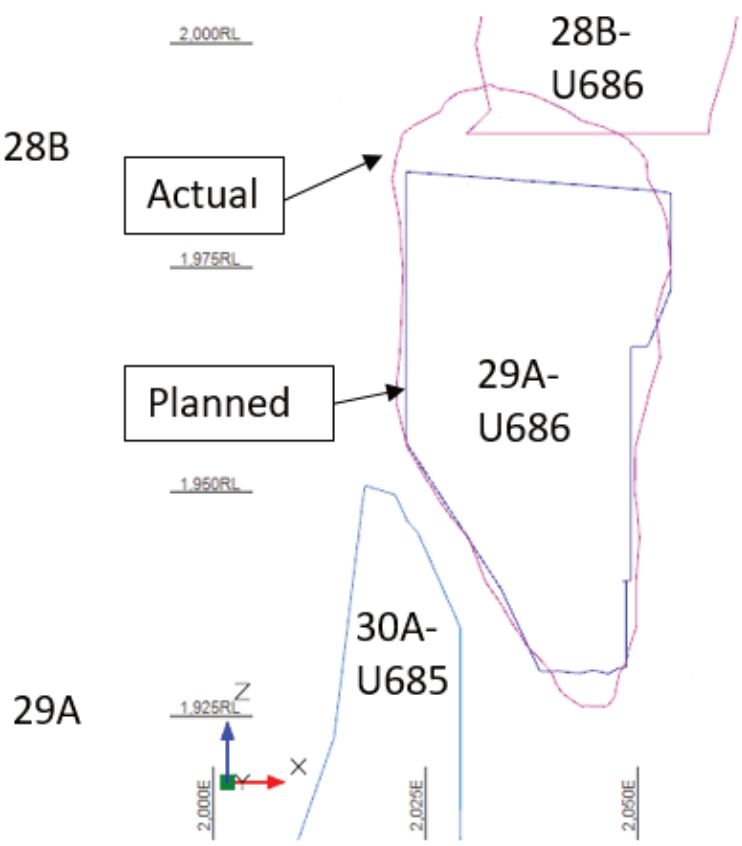

28B

29A

(b)

Figure 14 Cross-section north with planned (blue) and actual (pink) (a) 29A-U688 and (b) 29A-U686 extracted stopes 


\section{Conclusion}

A series of technical investigations was conducted to establish a new method of mining at Glencore's Mount Isa Mines to extract a high-grade crown pillar underneath and adjacent to paste filled stopes.

The investigations found that the CPB cured in situ strengths were almost always higher than lab cured and design strengths. This can be attributed to:

- Arching of stresses within the fill mass.

- Large size and height of the stopes.

- Curing processes increasing the in situ strength, including:

- Fast rate of filling.

○ Long travel times increasing mixing and de-hydrating.

○ High in situ temperatures.

The investigations confirmed and quantified the variance between design and in situ CPB strengths to ensure the underhand exposure dimensions were suitable.

The test data was incorporated into numerical modelling analyses and calibrated based on local site conditions. The refined model resulted in reliable analyses and forecasts to ensure safe and efficient extraction of stopes in the 29A block.

The modelling results demonstrated that underhand exposure of the $28 \mathrm{~B}$ stoping block could be achieved with minimal paste dilution. The underhand exposures were both stable and achieved the planned recoveries with minimal dilution.

The remaining stopes in the sequence are being optimised to increase the planned underhand exposure dimensions and overall efficiency of the block extraction with a risk-based approach.

Further CPB in situ strength investigations are recommended, including sampling by in situ drilling, with the intent of reducing the binder content to result in lower backfill costs whilst achieving the same function.

\section{Acknowledgement}

The authors acknowledge Glencore for permission to publish this paper. The authors thank Omer Yeni, David Matthews, Alastair Grubb, Geoffrey Potgieter and the core shed personnel for their contributions.

\section{References}

AMC Consultants 2012, MICO Backfill Discussions, Glencore consultant report, AMC Consultants, Perth.

Brummer, RK, Andrieux, PP \& O'Connor, CP 2003, 'Stability analyses of undermined sill mats for base metal mining', in RK Brummer, PP Andrieux, C Detournay \& R Hart (eds), Proceedings of the Third International FLAC Symposium, A.A. Balkema, Rotterdam.

Sainsbury, D \& Grubb, A 2010, 'Numerical analysis of extreme deformation and ground support performance at the N3500 Project', Proceedings of the Second Australasian Ground Control in Mining Conference, Australasian Institute of Mining and Metallurgy, Melbourne, pp. 233-246.

Veenstra, RL 2013, A Design Procedure for Determining the In Situ Stresses of Early Age Cemented Paste Backfill, PhD thesis, University of Toronto, Toronto. 